\title{
Announcements
}

The American Pediatric Society and Society for Pediatric Research announce the abstract deadline for the 1985 annual meeting (Washington, D. C., May 6-9) has been advanced to November 30, 1984. Inquiries and requests should be directed as follows.

\section{Society for Pediatric Research}

Debbie Wogenrich

Administrative Assistant, SPR

Department of Pediatrics

University of New Mexico School of Medicine

Albuquerque, NM 87131

Phone (505) 277-6628

American Pediatric Society

Pat Agatisa

Administrative Assistant, APS

Department of Pediatrics, Box 49

Downstate Medical Center

450 Clarkson Avenue

Brooklyn, NY 11203

Phone (212) 270-1693
The International Study Group for Diabetes in Children and Adolescents (I. S. G. D.) and the Department of Pediatrics of the University of Verona, Italy announce a winter course in the Management of Diabetic Youths to be held concomitantly with a winter camp for diabetic children in Misurina, Italy (near Cortina D'Ampezzo-Dolomite Alps) March 11-17, 1985.

The faculty will be composed of I. S. G. D. members from different countries, and the official language will be English.

During this course, practical and theoretical aspects of management will be discussed. The program will permit skiing. The course fee will be $\$ 300$, including hotel and full board. The course is addressed to physcians caring for diabetic youths.

Applicants should write prior to October 15, 1984 to Doctor L. Pinelli, Clinica Pediatrica, Policlinico, 37134 Verona, Italy. 